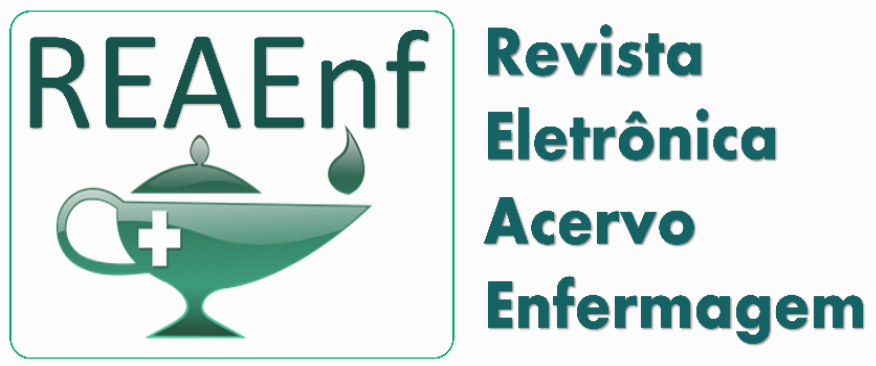

RELATO DE EXPERIÊNCIA

Recebido em: 8/2020

Aceito em: 10/2020

Publicado em: 1/2021

\title{
Doação de sangue: experiência exitosa na campanha enfermagem está no sangue
}

\author{
Blood donation: successful experience in the nursing campaign is in the blood
}

Donación de sangre: la experiencia exitosa en la campaña de enfermería está en la sangre

Niedja Carla Dias de Lira e Silva ${ }^{1 *}$, Priscila Cardoso de Santana ${ }^{2}$, Naedja Naira Dias de Lira e Silva ${ }^{3}$, Pollyana Souto da Silva ${ }^{4}$, Marcela Klyviann Bezerra de Vasconcelos ${ }^{2}$, Cleoma Santos e Santos ${ }^{2}$, Wellington Flávio Lopes dos Santos ${ }^{1}$, Luciene Regina de Lima ${ }^{5}$.

Resumo: Esse artigo buscou relatar a experiência vivenciada por voluntários na campanha enfermagem está no sangue. Trata-se de um estudo descritivo, tipo relato de experiência, realizado a partir da vivência de voluntários na campanha intitulada "Enfermagem está no Sangue". A qual ocorreu em uma cidade do Pernambuco, e durou o equivalente a uma semana, sendo finalizada com uma ação no dia 16 de junho de 2018. A campanha nasceu mediante o desejo dos estudantes em conscientizar a população para doação de sangue regular, buscando ampliar o quantitativo de doações, rompendo a barreira dos mitos e difundindo as verdades a cerca da doação de sangue. Permitindo que os não doadores entendessem a importância e quais os aspectos clínicos necessários para $o$ ato. A campanha alcançou os resultados esperados, também permitiu uma grande integração entre os envolvidos. Além de, resgatar as pessoas que não estavam em dia com suas doações, trouxe novos doadores que se comprometeram com a causa, fazendo seus cadastros nos hemocentros.

Palavras-chave: Comunicação, Enfermagem, Educação.

\begin{abstract}
This article sought to report the experience lived by volunteers in the nursing is in the blood campaign. It is a descriptive study, of the type of experience report, carried out from the experience of volunteers in the campaign entitled "Nursing is in the Blood". It took place in the city of Pernambuco, and lasted the equivalent of a week, ending with an action on June 16, 2018. Therefore, this campaign sought to increase the amount of donations, breaking the myth barrier and spreading the truths to about blood donation, so that non-donors understand the importance and what are the clinical aspects necessary for the act. The campaign achieved the expected results, it also allowed for a great integration between those involved. In addition, rescuing people who were not up to date with their donations, brought new donors who committed themselves to the cause, making their registrations in blood centers.
\end{abstract}

Keywords: Communication, Nursing, Education.

\footnotetext{
${ }^{1}$ Centro Universitário São Miguel (UNISÃOMIGUEL), Recife - PE. *E-mail: nikadias33@gmail.com

2 Centro Universitário Brasileiro (UNIBRA), Recife - PE.

3 Universidade Federal Rural do Semi-Árido (UFERSA), Mossoró - RN.

${ }^{4}$ Faculdade ALPHA, Recife - PE.

${ }^{5}$ Faculdade de Quixeramobim (UNIQ), Quixeramobim - CE.
} 
Resumen: Este artículo buscaba informar sobre la experiencia vivida por los voluntarios en la enfermería en la campaña de sangre. Es un estudio descriptivo, del tipo de informe de experiencia, realizado a partir de la experiencia de los voluntarios en la campaña titulada "Enfermería está en la sangre". Tuvo lugar en la ciudad de Pernambuco, y duró el equivalente a una semana, terminando con una acción el 16 de junio de 2018. Por lo tanto, esta campaña buscó aumentar la cantidad de donaciones, rompiendo la barrera del mito y difundiendo las verdades a sobre la donación de sangre, para que los no donantes entiendan la importancia y cuáles son los aspectos clínicos necesarios para el acto. La campaña logró los resultados esperados, también permitió una gran integración entre los involucrados. Además, el rescate de personas que no estaban al día con sus donaciones, trajo nuevos donantes que se comprometieron con la causa, haciendo sus registros en los centros de sangre.

Palabras clave: Comunicación, Enfermaría, Educación.

\section{INTRODUÇÃO}

O processo de doação de sangue é rápido e seguro, sendo um ato solidário e de cidadania. Consiste em doar o próprio sangue, uma única doação pode beneficiar até quatro vidas. E pode inclusive, salvar pessoas que se submetem a tratamentos de doenças crônicas, intervenções médicas de grande porte e complexidade, tais como, doenças oncológicas, cirurgias, ou situações de urgência (BRASIL, 2019).

O ciclo de doação de sangue compreende nove etapas: $1^{\circ}$ captação do doador para a doação voluntária. $2^{\circ}$ conscientização na qual é possível passar as informações de todo o processo aos voluntários, em seguida, na $3^{\circ}$ etapa ocorre o cadastro, momento no qual é preenchida uma ficha com dados de identificação do provável doador.

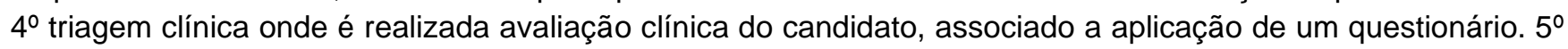
triagem hematológica onde é feita a análise da gota de sangue captada. $6^{\circ}$ coleta, que é a acoplagem de $450 \mathrm{ml}$ de sangue. $7^{\circ}$ triagem laboratorial das amostras. $8^{\circ}$ distribuição e $9^{\circ}$ procedimentos transfusionais (PEREIRA JR, et al., 2016).

Durante a triagem clínica, os possíveis doadores são submetidos a uma anamnese individual e sigilosa, que se trata de um diálogo mediado por uma entrevista semiestruturada com profissionais médicos. Será feita a verificação do estado clínico do possível doador, de maneira que, a coleta de sangue possa ocorrer em pessoas saudáveis, evitando futuros agravos aos doadores e/ou pacientes que receberão a hemotransfusão (FLAUSINO GF, et al., 2015).

O doador apto deve dispor de idade entre 16 e 69 anos e pesar mais de $50 \mathrm{~kg}$, no entanto, os menores de 18 anos devem estar sob autorização do responsável. Sobre o estado de saúde do doador, o mesmo deve estar alimentado, evitando alimentos gordurosos nas últimas horas que antecedem a doação, ter dormido no mínimo 6 horas nas últimas 24 horas, evitar fumar pelo menos 2 horas antes e não ter ingerido bebida alcoólica nas 12 horas anteriores. Sendo assim, para homens a frequência máxima é de 4 doações anuais, com pausa de 2 meses, e a mulher, 3 vezes ao ano, com pausa de 3 meses (BRASIL, 2016).

O Brasil possui alguns parceiros em projetos para o fortalecimento da doação voluntária. Porém, mesmo com alguns projetos, como por exemplo: "Doe Sangue Regularmente, Tem Sempre Alguém Precisando de Você", os hemocentros não ficam 100\% abastecidos (BRASIL, 2018). A doação é um ato de solidariedade espontânea, entretanto algumas vezes pode estar vinculado a determinado paciente conhecido, nesses casos, dá-se o nome de solidariedade orgânica (MARTINS MH, et al., 2018).

Em 25 de novembro é comemorado o Dia Nacional do Doador de Sangue, o qual tem por objetivo além de agradecer a todos os doadores de sangue, trazer a visibilidade da doação regular, bem como, sua importância na sociedade. Durante a semana em comemoração do doador, os serviços de hemoterapia de todo o país estão engajados em prol de campanhas para o fortalecimento da doação de sangue (BRASIL, 2015).

Os doadores de sangue além de favorecer alguém com sua atitude solidária, também, podem se apropriar de alguns direitos que the cabem, por exemplo, ao apresentar a carteira de doador, o benefício da meia entrada em estabelecimentos culturais, a isenção total ou parcial em concursos públicos e a folga no trabalho a cada 12 meses no ato da doação, segundo as consolidações das leis trabalhistas (TASSO NAM, 2018). 
Diante disso, com o intuito de disseminar a importância, e conscientizar a população sobre o abastecimento dos hemocentros, tendo em vista o valor em ser solidário com qualquer pessoa que necessite da vida que 0 sangue humano pode ofertar a qualquer indivíduo. Discentes de enfermagem se impulsionaram a promover uma campanha de grande responsabilidade social. Portanto, a campanha enfermagem está no sangue teve o propósito de viabilizar o engajamento em prol da doação voluntária de sangue. Dessa forma, o presente trabalho visa relatar a experiência vivenciada por voluntários na campanha enfermagem está no sangue.

\section{RELATO DE EXPERIÊNCIA}

Trata-se de um estudo descritivo, do tipo relato de experiência, realizado a partir da vivência de voluntários na campanha intitulada "Enfermagem está no sangue". Idealizada por discentes de enfermagem, de instituições públicas e privadas, membros de diretórios acadêmicos, comitês estudantis e representantes de turma. A campanha ocorreu em uma cidade do estado do Pernambuco, e durou o equivalente a uma semana, sendo finalizada com uma ação no dia 16 de junho de 2018.

Assim, a campanha nasceu mediante o desejo dos estudantes em conscientizar a população para doação de sangue regular, a começar por instituições de ensino superior de enfermagem da região metropolitana do Recife. A proposta seria uma mobilização, por meio de uma campanha que contou com o apoio do Conselho Regional de Enfermagem, lideranças estudantis, e o hemocentro de referência no Estado do Pernambuco.

Representantes de cada instituição participante levaram o convite da campanha, mediante divulgação por redes sociais, a fim de convidar outras pessoas a fazerem parte da equipe, inclusive também parcerias. Posteriormente, foram agendadas reuniões para definir local, horário e insumos necessários para a realização. Definida a equipe organizadora, e o projeto pronto para execução, seguiu a divulgação para a população em geral, logo, os sites das instituições envolvidas, também as redes sociais da campanha divulgaram informações pertinentes que envolviam o processo da doação, bem como o ciclo do sangue e suas etapas, sanando assim possíveis dúvidas.

Foram confeccionados cartazes para a exposição em centros universitários e hospitais, com informações pertinentes a campanha, o dia da ação e os serviços oferecidos, bem como, o endereço eletrônico referente ao projeto. Alcançando, desse modo, o público-alvo da campanha, que seriam além dos estudantes e profissionais de enfermagem, toda população dentro dos pré requisitos para a doação de sangue.

O hemocentro de referência no estado foi escolhido para concentrar as doações durante a campanha, com o seu apoio foi possível realizar as ações. Tudo foi preparado para receber os possíveis doadores e serem bem recepcionados. Profissionais trabalharam exercendo suas atribuições, desde a recepção com o acolhimento até o momento pós doação. Entre a espera da triagem, algumas palestras foram ministradas para esclarecimento sobre doação/hemotransfusão, inclusive sobre o cadastro para doação de medula óssea.

Iniciada a campanha, cada indivíduo se deslocava ao hemocentro para fazer sua doação, portando seus documentos pessoais, e logo na recepção se identificava como voluntário, para que assim ao término fosse possível estimar quantas pessoas foram alcançadas pela mobilização. Ao sair, os voluntários recebiam um adesivo com o símbolo da campanha: uma gota de sangue, representando a gratidão por seu gesto, chamando a atenção para a causa coletiva, e um cartão autoeducativo orientando sobre sua possível próxima doação.

No final da campanha foi realizada uma grande ação aberta ao público em uma praça da cidade. Para isso, foi contactada a prefeitura da cidade para liberação do local e apoio no dia da ação. A praça foi ornamentada e preparada para a oferta de alguns serviços. Para os voluntários foram confeccionadas camisas com o nome da campanha e a frase "uma doação pode salvar quatro vidas, doe vida!" podendo assim identificar cada organizador responsável.

Então, em 16 de junho de 2018, a ação durou todo o dia das $8 \mathrm{~h}$ às $17 \mathrm{~h}$. Logo no início, foi ofertado um café da manhã com comidas leves e frutas para os voluntários que estavam na organização e para os que estariam indo fazer suas doações posteriormente. Estudantes e profissionais de enfermagem fizeram orientações de saúde na praça, também foi feita aferição de pressão arterial ao público em geral. Outros profissionais ofertaram 
massagens relaxantes para quem estava passando pelo local. Houve também distribuição de preservativos femininos e masculinos, bem como, orientação sobre infecções sexualmente transmissíveis (IST).

Grupos de maracatu e orquestras em trio elétrico fizeram parte dos momentos de interação e divertimento. Também, palhaços terapeutas marcaram presença na abordagem a população durante o dia. Faixas informativas da campanha foram expostas nos sinais de trânsito, próximas ao local de doação, da mesma forma foram distribuídos informes e adesivos, a fim de causar a visibilidade da ação.

\section{DISCUSSÃO}

O dia 14 de junho é reconhecido como o Dia Mundial do Doador de Sangue. Em todo o mundo são organizadas ações e eventos que objetivam conscientizar sobre a necessidade de se fazer doações regulares de sangue para garantir que todos os indivíduos e comunidades tenham acesso a produtos sanguíneos seguros como parte integral da saúde universal (BRASIL, 2020). Prontamente, a ação de encerramento da campanha se deu na semana do doador, em junho de 2018.

Logo, essa campanha buscou ampliar o quantitativo de doações, onde se faz necessário por vezes romper a barreira dos mitos, difundindo as verdades sobre a doação de sangue, para que os não doadores entendam a importância e quais os aspectos clínicos necessários para o ato. Cabe enfatizar que o sangue é insubstituível, a doação voluntária é a única fonte para sua transfusão, e os estoques ainda são insuficientes para atender as demandas do país (SILVA GEM e VALADARES GV, 2015).

Entende-se que a falta de conhecimento da população sobre o assunto, reflete diretamente nas dificuldades de compreensão e adesão ao processo de doação de sangue. Estudos apontam que estão entre as problemáticas mais frequentes, no que concerne a essa temática: a falta de instrução, a falta de engajamento dos profissionais na atenção primária para elucidar dúvidas recorrentes sobre o perfil dos doadores de sangue. Tais dificuldades podem ser sanadas com a devida orientação, e implementação de campanhas, que possam possibilitar a disseminação de notícias, impulsionando a realização de ações com essa abordagem, dentro das comunidades em que a equipe de saúde atua (CORD D, et al., 2015).

Por tanto, o engajamento dos estudantes de enfermagem em articular ações na área de saúde, se dá pelo incentivo em adotar hábitos que repercutam impactos positivos a população, além de, serem agentes de educação em saúde, inclusive na área de hemoterapia. Tais conhecimentos devem ser compartilhados para encorajar novos doadores aos hemocentros (PEREIRA TS e BASTOS JL, 2019). Ademais, foi necessário alcançar inclusive a população que porventura, não possa doar, seja por motivo de saúde ou pessoal, com o intuito de assegurar a educação em saúde a todos.

É evidenciado que indivíduos que se envolvem em atos solidários, têm maior prevalência entre os doadores de sangue, estes já estão habituados em serem generosos com pessoas das quais as vezes desconhecem, mas que por algum motivo um dia precisaram de sua ajuda. No quesito doador, não é necessário ofertar algo material que possa causar uma falta posteriormente, basta somente atender os requisitos de saúde dos quais as autoridades em saúde recomendam. Uma vez que o volume de sangue é recuperado pelo organismo humano em algumas horas, e seus componentes sanguíneos em poucas semanas (BRASIL, 2001).

A envoltura em ações solidárias por parte de discentes da área de enfermagem, enriquece o processo de formação profissional. Levando em consideração princípios da bioética e do Sistema Único de Saúde (SUS), além de observância às políticas de saúde, geram reflexões a cerca da empatia com os participantes e instiga a visão holística ao ser humano (SAPIRO A e MATTIELLO R, 2016).

Mesmo diante de algumas dificuldades enfrentadas durante a campanha, os voluntários optaram por manter a motivação em realizar aquilo que foi proposto no planejamento inicial. Destarte, parte dessa percepção está associada ao desejo em levar a todos, o acesso à ações de educação em saúde, bem como, o atendimento de demandas necessárias ao público que irá se beneficiar dos frutos da campanha. A experiência em lidar com os percalços durante a ação, proporcionou aos voluntários a desenvoltura de habilidades, além do exercício do trabalho em equipe. Cabe ressaltar que para atingir os resultados esperados, foi preciso a disponibilidade de todos envolvidos, movidos de um objetivo em comum (SALAZAR KA, et al., 2015). 
Diante disso, foi notório que a campanha enfermagem está no sangue contribuiu com a incidência das doações de sangue. Embora, não foi possível quantificar em números os doadores durante toda a semana, sabemos que seus hemoderivados puderam ser uma fonte de vida, oriundos da campanha para os pacientes que necessitaram.

A campanha de doação de sangue alcançou os resultados esperados por parte dos discentes que se disponibilizaram no planejamento e implementação. Permitiu uma integração entre órgãos, instituições e população em geral. Além de resgatar as pessoas que não estavam em dia com suas doações, trouxe novos doadores que se comprometeram com a causa, fazendo seus cadastros nos hemocentros. Representou uma experiência exitosa, permitindo que a solidariedade e o amor pelo cuidar que a profissão de enfermagem exerce, unissem estudantes e profissionais com um objetivo em comum, podendo assim alcançar uma expressiva população que se dispôs em participar da iniciativa.

\section{REFERÊNCIAS}

1. BRASIL, Ministério da Saúde, Biblioteca Virtual em Saúde, 14/6 - Dia Mundial do Doador de Sangue.

2. BRASIL, Ministério da Saúde. Caderno de informação: sangue e hemoderivados: dados de 2016. Ministério da Saúde. 2018.

3. BRASIL, Ministério da Saúde. Manual de Orientações para Promoção da Doação Voluntária de Sangue. 1st ed. e atual. Brasília - DF: Ministério da saúde; 2015. 1-154 p. 1 vol.

4. BRASIL, Ministério da Saúde. Portaria no 158, de 4 de fevereiro de 2016. Ministério da Saúde: Redefine o regulamento técnico de procedimentos hemoterápicos. 2016.

5. BRASIL, Ministério da Saúde. Secretaria de Atenção à Saúde. Doação de sangue: como doar, quem pode doar, impedimentos. Disponível em: http://www.saude.gov.br/saude-de-a-z/doacao-de-sangue. Acesso em 24 jun. 2020.

6. BRASIL, Ministério da Saúde. Triagem Clínica de Doadores de Sangue. - Brasília: Ministério da Saúde, Coordenação Nacional de Doenças Sexualmente Transmissíveis e Aids. 2001.

7. CORD D, et al. As significações de profissionais que atuam no programa saúde na escola (PSE) acerca das dificuldades de aprendizagem: patologização e medicalização do fracasso escolar. Psicologia Ciência e Profissão, 2015; 35:40-53.

8. FLAUSINO GF, et al. O ciclo de produção do sangue e a transfusão: o que o médico deve saber. Rev Med Minas Gerais. 2015;25(2):269-279.

9. MARTINS MH, et al. A Importância do Banco de Sangue no Cenário Hemoterápico. Centro Universitário UNISEP. 2018;1 6.

10. PEREIRA JR, et al. Doar ou não doar, eis a questão: uma análise dos fatores críticos da doação de sangue. Ciência \& Saúde Coletiva,2016;21:2475-2484.

11. PEREIRA TS, BASTOS JL. Doação de sangue entre estudantes de medicina da Universidade Federal de Santa Catarina. Arquivos Catarinenses de Medicina, 2019; 38(2):1-7 ed. 2, p. 1-7.

12. SALAZAR KA, et al. As Relações simbólicas e a motivação no trabalho voluntário. Rev. ADM, Mackenzi, 2015;16(3)1: 171-200.

13. SAPIRO A, MATTIELLO R. Voluntariado: benefício a quem presta e a quem recebe. Sci Med,2016;26(4):1-4.

14. SILVA GEM, VALADARES GV. Conhecendo os Meandros da Doação de Sangue: Implicações para a Atuação do Enfermeiro na Hemoterapia. Rev. Bras. Enferm. 2015; 68(1).

15. TASSO NAM. Doação de sangue: aspectos sociodemográficos e análise evolutiva Dissertação (Mestrado em Psicobiologia). Centro de Biociências, Universidade Federal do Rio Grande do Norte; 2018;109 p. 